\title{
Suprakondiler humerus kırıklarının klinik sonuçları: Kapalı - açık redüksiyonun karşılaştırılması
}

\section{Clinical results of supracondylar humerus fractures: Comparison of closed- open reduction}

\author{
Atilla Çıtlak 1 \\ 1 Karadeniz Teknik Üniversitesi, Tıp Fakültesi, Ortopedi ve Travmatoloji Anabilim Dalı, Trabzon, Türkiye
}

\section{Öz.}

Amaç: Suprakondiler humerus kırıkları çocuklarda en sık görülen yaralanmalar arasındadır. Gartland tip 2 ve 3 kırıkların tedavisinde kapalı veya açık redüksiyondan sonra perkutan pinleme uygulanır. Bu çalıșmanın amacı Gartland tip 2 ve 3 suprakondiler humerus kıııklarında klinik sonuçları ve kapalı- açık redüksiyonun sonuçlara etkisini değerlendirmektir.

Materyal ve metot: Çalışmamıza 2015-2018 yılları arasında suprakondiler humerus kııı̆ı nedeniyle tedavi edilen, Gartland tip 2 ve 3 kıı̆ğı olan, 10 yaşın altında olan, en az 3 ay takibi olan 48 hasta dahil edildi. Hastaların medikal kayıtlarından ve radyografilerinden elde edilen veriler değerlendirildi. Hastaların demografik bilgileri, kırık geçirdiği taraf, kırık tipi, pin konfigürasyonu, cerrahi yapılana kadar geçen zaman, takip süresi kaydedildi. Radyografilerinde ölçülen Baumann açıları, son kontrolde değerlendirilen eklem hareket açıkıkları ve taşıma açıları değerlendirildi. Sonuçlar Flynn kriterleri kullanılarak değerlendirildi. Hastalar kapalı redüksiyon uygulananlar (Grup 1), açık redüksiyon uygulananlar (Grup 2) olmak üzere iki gruba ayrıldı ve sonuçlar karşılaştırıldı.

Bulgular: Hastaların ortalama yaşı 5,94'dü(1-10yaş). 21 hastadan oluşan kapalı redüksiyon grubu (Grup 1) ve 27 hastadan oluşan açık redüksiyon grubu (Grup 2) arasında yaş, cinsiyet ve etkilenen taraf açısından fark yoktu. Hastalar ortalama 11,06 saat sonra (8-48 saat) ameliyata alındı ve ortalama 18,60 ay (3-44 ay) takip edildi. Gruplar arasında ameliyata alınma zamanı ve takip süresi açısından fark yoktu. Flynn kriterlerine göre 43 hastada $(\% 89,5)$ mükemmel ve iyi sonuc elde edildi. Grup 1'deki hastaların Flynn kriterlerine göre 20'sinde (\%95,2) mükemmel ve iyi sonuç elde edildi. Grup 2'deki hastaların Flynn kriterlerine göre 22'sinde $(\% 81,5)$ mükemmel ve iyi sonuç elde edildi. 3 hastada orta sonuç $(\% 11,1), 2$ hastada $(\% 7,4)$ kötü sonuç elde edildi. Gruplar karşılaştırıldığında kapalı redüksiyon grubunda mükemmel ve iyi sonucun daha fazla oranda olduğu görüldü, fakat istatistiksel olarak anlamlı fark yoktu.

Sonuç: Suprakondiler humerus kırıklarının tedavisinde kapalı ve açık redüksiyon sonrasında pinlerle fiksasyon etkili ve güvenli bir tedavi yöntemidir. Öncelikle kapalı redüksiyon uygulanmalıdır, fakat kapalı redüksiyon sağlanamazsa açık redüksiyon da tatminkar sonuçlar sunar. Bu çalışmada kapalı- açık redüksiyonla tedavi edilen hastaların klinik sonuçları arasında anlamlı fark tespit edilmedi. Kapalı- açık redüksiyonun klinik sonuçlar üzerine etkisini daha iyi değerlendirebilmek için, daha fazla sayıda hasta içeren prospektif çalışmalar yapılabilir.

Anahtar kelimeler: Humerus kırıkları, Dirsek, Kapalı kırıklar, Açık kırık redüksiyonu.

Abstract

Background: Humerus supracondylar fractures are among the most common injuries in children. Percutaneous pinning is applied after closed or open reduction for the treatment of Gartland type 2 and 3 fractures. The aim of this study is to evaluate the clinical results in Gartland type 2 and 3 humerus supracondylar fractures and the effect of closed- open reduction on results.

Methods: Between 2015- 2018, 48 patients who were treated for Gartland type 2 and 3 humerus supracondylar fractures, below 10 years, minumum 3 months follow-up were included in our study. The data which were obtained from medical records and radiographs were evaluated. Demographic data, fracture side, fracture type, pin configuration, time to surgery, follow-up time were recorded. Measured Baumann angles on radiographs, range of motions and carrying angles on last follow-up were evaluated. Postoperative results were evaluated by using Flynn criteria. Patients were divided into two groups as patients were treated with closed reduction (Group 1), treated with open reduction (Group 2), and results were compared. Results: Mean patient age was 5,94 (1-10 years). Group 1 (21 patients) and Group 2 (27 patients) were not different according to patient age, sex and fracture side. Patients were operated after a mean of 11,06 hours (8- 48 hours), and the mean follow-up was 18,60 months (3- 44 months). The groups were not different according to time to operation and follow-up period. Excellent and good results were obtained in 43 patients $(89,5 \%)$ according to Flynn criterias. Excellent and good results were obtained in 20 patients $(95,2 \%)$ according to Flynn criterias in Group 1. Excellent and good results were obtained in 22 patients $(81,5 \%)$ according to Flynn criterias in Group 2. Fair results were obtained in 3 patients $(11,1 \%)$, poor results in 2 patients $(7,4 \%)$. In comparison, more excellent and good result rates were seen in closed reduction group, but there was no statistically significant difference.

Conclusions: Percutaneus pinning after closed and open reduction is effective and safe in the treatment of humerus supracondylar fractures. First closed reduction must be performed, but if closed reduction could not obtained, open reduction serves satisfactory results. In this study, there was no significant difference between patients who were treated with closed or open reduction. For better evaluation of the effect of closed- open reduction on clinical results, prospective studies with more patients could be performed.

Keywords: Humeral fractures, Elbow, Closed fractures, Open fracture reduction.

\section{Sorumlu Yazar $I$ Corresponding Author}

Dr. Atilla ÇITLAK

Karadeniz Teknik Üniversitesi, Tıp Fakültesi

Ortopedi ve Travmatoloji Anabilim Dalı, 61080 Trabzon, Türkiye

Tel: 0(505) 3786196

e-mail: atillacitlak@yahoo.com

Geliş tarihi / Received: 18/03/2019

Kabul tarihi / Accepted: 10/05/2019

DOI:10.35440/HUTFD.541519 


\section{Giriş}

Suprakondiler humerus kırıkları çocuklarda en sık görülen yaralanmalar arasındadır (1). Bu kırıklar tüm pediatrik kırıkların \%10'unu, tüm pediatrik dirsek yaralanmalarının ise yaklaşık \% 75 'ini oluşturur $(2,3)$. Açık el üzerine düşme en sık görülen yaralanma mekanizmasıdır. Kırık Gartland sınıflaması ile değerlendirilir. Gartland tip 1 kırıklar stabildir, Gartland tip 2 ve 3'de deplasman ve angulasyon vardır $(4,5)$. Kırıktaki deplasman çevre yumuşak dokular$\mathrm{da}$, brakial arterde, median ve radial sinirde yaralanma oluşturabilir (6).

Gartland tip 2 ve 3 kırıkların tedavisinde altın standart mümkün olan en kısa sürede kapalı redüksiyon perkutan pinlemedir. Medial ve lateral kolon dizilimi sağlanmalı, anterior humeral çizgi kapitellumun orta 1/3'ünden geçmeli ve Baumann açısı restore edilmelidir. Az miktarda rotasyon tolere edilebilse de varus dizilim kabul edilemez (7). Kapalı yöntemlerle redüksiyon gerçekleştirilemediğinde açık redüksiyon ve perkutan pinleme kabul edilen tedavi yöntemidir (8).

Perkutan pinleme konfigürasyonları çapraz pinleme ve izole lateral pinlemedir. Çapraz pinlemede daha iyi fiksasyon sağlanabilmekte fakat iatrojenik ulnar sinir hasarı gelişebilmektedir. Optimal pin konfigürasyonu tartışmalıdır (9).

Bu çalışmanın amacı Gartland tip 2 ve 3 suprakondiler humerus kırıklarında klinik sonuçları ortaya koymak ve kapalı- açık redüksiyonun klinik sonuçlara etkisini değerlendirmektir.

\section{Materyal ve metod}

Ortopedi ve Travmatoloji kliniğimizde 2015-2018 yılları arasında suprakondiler humerus kırı̆ı nedeniyle tedavi edilen hastaların retrospektif değerlendirilmesi yapıldı. Çalışma için kurumumuz etik kurulundan izin alındı. ÇaIışmaya katılan hastaların vasilerinden bilgilendirilmiş onam alındı. Bu çalışma 2008 Helsinki deklarasyonu prensiplerine uygun olarak yapıldı. Gartland tip 2 ve 3 kırı̆ı̆ olan, 10 yaş ve altında olan, en az 3 ay takibi olan 48 hasta çalışmaya dahil edildi. Açık kırıklar, başvuru anında vasküler yaralanması olan hastalar, multitravma geçirmiş olan hastalar çalışma dışı bırakıldı.

Hastaların medikal kayıtlarından, preoperatif, postoperatif ve son kontrol radyografilerinden elde edilen veriler değerlendirildi. Hastaların demografik bilgileri, kırık geçirdiği taraf, kırık tipi, pin konfigürasyonu, cerrahi yapılana kadar geçen zaman, takip süresi kaydedildi. Hastalarda postoperatif komplikasyon veya enfeksiyon gelişip gelişmediği kontrol edildi. Radyografilerinde ölçülen Baumann açıları (10), son kontrolde değerlendirilen eklem hareket açıklıkları ve taşıma açıları değerlendirildi.

Elde edilen verilerle postoperatif sonuçlar Flynn kriterleri kullanılarak değerlendirildi (11) (Tablo 1). Hastalar kapalı redüksiyon uygulananlar (Grup 1) ve açık redüksiyon uygulananlar (Grup 2) olmak üzere iki gruba ayrıldı. Gruplar kendi arasında elde edilen veriler ve klinik sonuçlar açısından karşılaştırıldı.

Tüm hastalar ameliyat hazırlığı yapıldıktan sonra ameliyat odasına alındı. Genel anestezi altında uygun saha temizliği ve örtünmeyi takiben traksiyon ve maniplasyon uygulandı. Uygun redüksiyon sağlandığı görülen hastalara peruktan pinlerle fiksasyon yapıldı. Kapalı yöntemlerle redüksiyon sağlanamayan hastalar ise lateral veya medial açık redüksiyon sonrasında pinlerle fiksasyon sağlandı. Medial pinlemede mini insizyon yapılarak ulnar sinirin korundu.

Tablo 1. Flynn kriterleri

\begin{tabular}{lcc}
\hline Sonuç & Taşıma açısı kaybı & Hareket kaybı \\
\hline Mükemmel & $0-5$ derece & $0-5$ derece \\
lyi & $6-10$ derece & $6-10$ derece \\
Orta & $11-15$ derece & $11-15$ derece \\
Kötü & $>15$ derece & $>15$ derece \\
\hline
\end{tabular}

Kırık proksimalindeki metafizyel ucun yerleşimine ve distal fragman deplasmanına göre medial veya lateral yaklaşım tercih edildi. Lateral yaklaşımda lateral suprakondiler ridge üzerinden insizyon yapılarak brakioradialis ve triseps kasları arasındaki plandan kemiğe kadar diseksiyon yapıldı. Geniş yaklaşım içinse anconeus ve ekstansör karpi ulnaris kasları arasındaki Kocher intervali kullanıldı. Radial sinir hasarı oluşmaması için insizyon lateral epikondilden proksimale 6-7 cm'den fazla uzatılmadı. Hematom boşaltılıp kırık uçlarına tuzaklanmış yapılar serbestleştirildi. Görülerek redüksiyon yapılıp pinlerle fikse edildi. Skopi ile kontrol edildi. Medial yaklaşım ise posterolaterale deplase kırıklarda kullanıldı. Medial epikondilin palpasyonundan sonra dirsek medialinden insizyon yapıldı. Ulnar sinire kadar diseksiyona devam edilip ulnar sinir eksplore edildi ve korundu. Künt diseksiyonla proksimal parçanın distali ortaya konulup hematom boşaltıldı, tuzaklanan yapılar serbestleştirildi. Görülerek redüksiyon gerçekleştirildi. Ulnar sinir korunarak pinler yerleştirildi. Skopi kontrolü yapııdı. Tüm hastalarda stabil pinleme gerçekleştirildikten sonra skopi ile yan görüntüde anterior humeral çizginin kapitellum orta 1/3'ünden geçtiği görüldü, ön arka görüntüde ise Baumann açısı ölçülerek uygun redüksiyonun sağlandığı görüldü. Peruktan pinlerin ucu büküldü. 90 derecede uzun kol ateline alınarak yakın nörovasküler takibe alındı. 4 hafta sonrasında atel sonlandırılıp hareket başlandı, pinler de poliklinik ortamında çekildi.

Tüm istatistiksel değerlendirmeler SPSS 24 (SPSS Inc., Chicago, IL) kullanılarak yapıldı. İki bağımsız grubun karşılaştırıması için ki-kare testi kullanıldı. Gruplar arasında sürekli değişkenleri karşılaştırmak için student $t$ test kullanıldı. P değeri için $<0,05$ anlamlı kabul edildi. 


\section{Bulgular}

Çalışmaya dahil edilen 48 hastanın 33'ü erkek $(\% 68,7)$, 15 'i kadındı (\%31,3). Hastaların ortalama yaşı 5,94'dü (110yaş). 22 hastanın $(\% 45,8)$ sağ dirseğinden, 26 hastanın $(\% 54,2)$ sol dirseğinden kırık geçirdiği görüldü. 21 hastadan oluşan kapalı redüksiyon grubu (Grup 1) ve 27 hastadan oluşan açık redüksiyon grubu (Grup 2) arasında yaş, cinsiyet ve etkilenen taraf açısından anlamlı fark yoktu. Hastalar ortalama 11,06 saat sonra (8-48 saat) ameliyata alındı ve ortalama 18,60 ay (3-44 ay) takip edildi. Grup 1'de cerrahi uygulanana kadar geçen zaman ortalama 11,7 saat (8-48 saat) ve takip süresi ortalama 19,04 aydı (3-44 ay). Grup 2'de cerrahi uygulanana kadar geçen zaman ortalama 10,5 saat (8-24 saat) ve ortalama takip süresi 18,25 aydı (4-44 ay). Gruplar arasında cerrahi uygulana kadar geçen zaman ve ortalama takip süresi açısından anlamlı fark yoktu.

Değerlendirilen 48 hastanın 22'si $(\% 45,8)$ Gartland tip 2, 26 'sı $(\% 54,2)$ Gartland tip 3 kırık geçirmişti. Grup 1'deki 21 hastanın 12'si $(\% 57,1)$ Gartland tip 2, 9'u $(\% 42,9)$ Gartland tip 3 kırık; Grup 2'deki 27 hastanın 10'u (\%37,0) Gartland tip 2, 17'si $(\% 63,0)$ Gartland tip 3 kırık geçirmişti. Kapalı redüksiyon grubunda Gartland tip 2 kırık, açık redüksiyon grubunda ise Gartland tip 3 kırık sayısısı fazlaydı.

Ortalama Baumann açısı 74,77 dereceydi (67-86 derece). Grup 1'de ortalama Baumann açısı 73,33 dereceydi (6880 derece). Grup 2'de ortalama Baumann açıSı 75,88 derceydi (67-86 derece). Gruplar arasındaki fark anlamlı değildi $(p=0,87)$.

Flynn kriterlerine göre 43 hastada $(\% 89,5)$ mükemmel ve iyi sonuç elde edildi. Grup 1'deki hastaların Flynn kriterlerine göre 20'sinde $(\% 95,2)$ mükemmel ve iyi sonuç elde edildi (Şekil 1). Kötü sonuç elde edilen bir hasta nabızsız pembe el nedeniyle takip edilip postop ilk gününde dolaşımın bozulması nedeniyle arteryel eksplorasyon yapılan hastaydı. Grup 2'deki hastaların Flynn kriterlerine göre 22 'sinde $(\% 81,5)$ mükemmel ve iyi sonuç elde edildi (Şekil 2). 3 hastada orta sonuç $(\% 11,1), 2$ hastada $(\% 7,4)$ kötü sonuç elde edildi. Kötü sonuçlanan hastaların birinde de kubitus varus deformitesi gelişti. Gruplar karşılaştııldığında kapalı redüksiyon grubunda mükemmel ve iyi sonucun daha fazla oranda olduğu görüldü, fakat gruplar arasında anlamlı fark yoktu $(p=0,15)$.

Redüksiyon sonrası fiksasyon için kullanılan pinlerin konfigürasyonu; 18 hastada $(\% 37,5)$ lateral pinleme, 30 hastada $(\% 62,5)$ çapraz pinleme şeklindeydi. Çapraz pinlemede en sık kullanılan pin konfigürasyonu lateralde 2 pin, medialde tek pin şeklinde 24 hastaya uygulandı. Grup 1 'de fiksasyon için 10 hastada $(\% 47,6)$ lateral pinleme, 11 hastada $(\% 52,4)$ çapraz pinleme yapıldı. Grup 2 'de 8 hastada $(\% 29,6)$ lateral pinleme, 19 hastada $(\% 70,4)$ çapraz pinleme yapıldı. Grup 2'de çapraz pinleme oranı fazlaydı. Lateral pinleme ve çapraz pinleme arasında anlamlı fark yoktu $(p=0,20)$.

Hiçbir hastada redüksiyon kaybı veya derin enfeksiyon gelişmedi. 2 hastada görülen pin dibi enfeksiyonu pansumanla takip edildi, pinler çekilince tamamen düzeldi.
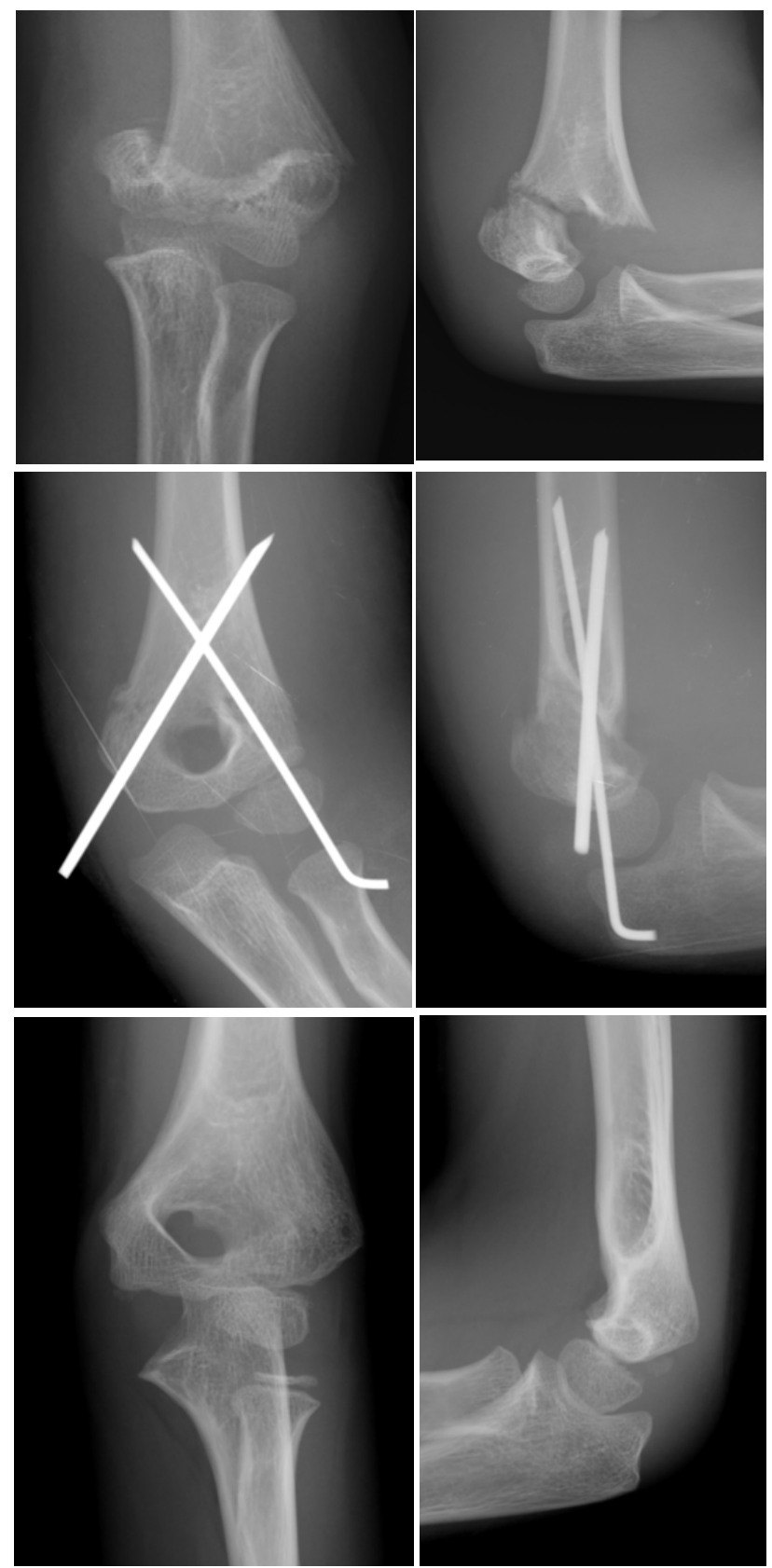

Şekil 1. 6 yaşında erkek hasta Gartland tip 2, kapalı redüksiyon pinleme, 8 ay takip

\section{Tartışma}

Suprakondiler humerus kırıkları çocuklarda sık görülen bir yaralanmadır. Deplase kırıklarda cerrahi tedavi yöntemi daha uygundur. Kapalı redüksiyon perkutan pinleme standart tedavi yöntemidir. Kapalı redüksiyonun gerçekleştirilemediği durumlarda açık redüksiyon uygulanır (12). Bu çalışmada suprakondiler humerus kırıklarının sonuçları ve kapalı- açık redüksiyonun sonuçlar üzerine etkisi 
değerlendirildi.

Hastalar ameliyat hazırlığı tamamlandıktan sonra en kısa süre içinde ameliyata alındı. Başka kliniklerden sevk edilen hastaların ameliyata alınması için geçen süre daha fazlaydı. Hastalar ortalama 11,06 saat sonra ameliyata alındı. Kapalı- açık redüksiyon grupları arasında bu süre açısından fark yoktu. Suprakondiler humerus kırığına müdahalede gecikmenin kapalı redüksiyon gerçekleştirilememesi sonucunda açık redüksiyona geçme oranını artırdığı gösterilmiştir (13). Bu hastaların 12 saat içinde tedavi edilmesi daha uygundur $(13,14)$.
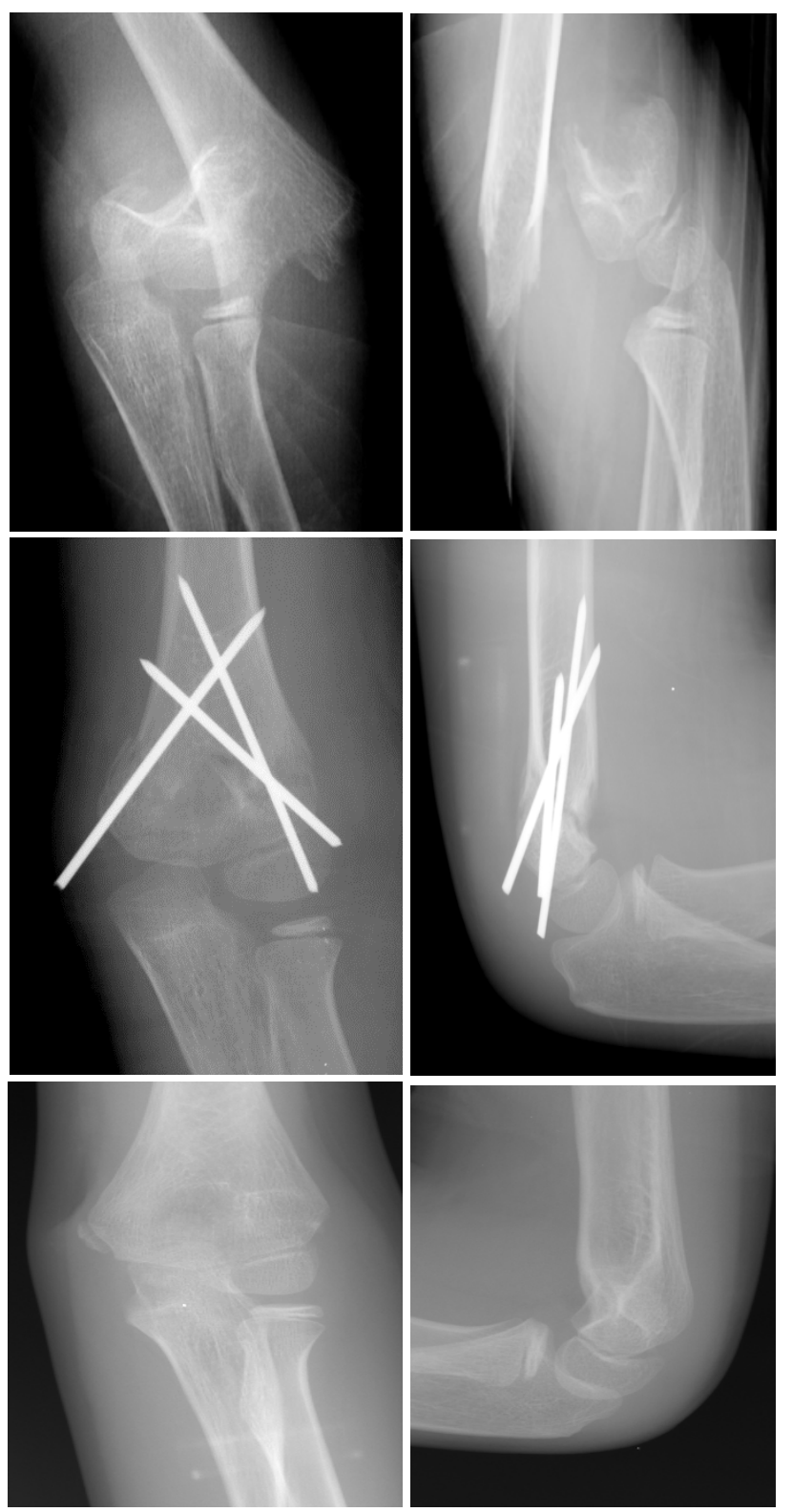

Şekil 2. 7 yaşında erkek hasta Gartland tip 3, açık redüksiyon pinleme, 20 ay takip

Açık redüksiyon için farklı yaklaşımlar mevcuttur. Yaralanması muhtemel yapılara direk ulaşım sağlaması, iyi kozmetik ve fonksiyonel sonuçlar sağlaması anterior yaklaşımın avantajlarıdır. Distal fragman deplasmanına göre medial ve lateral yaklaşım da önerilmektedir (15). Posterior yaklaşımda diğer yaklaşımlara göre daha az tatminkar sonuçlar elde edilmiştir (16). Enfeksiyon oranı, kompartman sendromu, kaynama süresi, iatrojenik sinir yaralanması açısından bu yaklaşımlar arasında anlamlı fark yoktur (15). Bu çalışmada da benzer şekilde kullanılan lateral ve medial yaklaşım arasında fark görülmedi.

Baumann açısı suprakondiler humerus kırığında redüksiyonun değerlendirilmesi için önemlidir $(10,17)$. Gruplar arasında Baumann açısı yönünden anlamlı fark görülmedi. Açık redüksiyon grubunda bir hastada kubitus varus gelişti. Yan grafide anterior humeral çizginin kapitelumun anterior veya orta $1 / 3$ 'ünden geçmesi daha iyi hareket açıklğı ile sonuçlanır (18). Tüm hastalarda bu kriterin sağlanmasının eklem hareket açıkığı üzerine olumlu etkisinin olduğu düşünüldü.

Kapalı redüksiyon uygulandıktan sonra 2-3 lateral pin uygulanması önerilmektedir (12). Biyomekanik olarak medial ve lateral pin daha fazla stabilite sağlamasına rağmen medial pin ulnar sinirde yaralanma riski oluşturur $(3,12)$. Pin konfigürasyonları 2 lateral pin, 2 çapraz pin, 3 lateral pin, 3 çapraz pin şeklindedir. Slobogean ve ark lateral pinleme ile çapraz pinlemeyi karşılaştırmış ve çapraz pinleme yapılan her 28 hastanın birinde iatrojenik sinir hasarı olduğunu göstermişlerdir (19). Worataranat ve ark lateral pinlemenin ulnar sinir hasarı olmadan, çapraz pinleme ile benzer sonuçlar sunduğunu göstermişlerdir (20). İki veya üç lateral pinin kırık hattında optimal fiksasyon sağladığı da gösterilmiştir (21). Fakat Zamzam ve ark lateral pinlemenin redüksiyon kaybına, komplikasyonlara ve reoperasyona yol açı̆ı̆ını bildirmişlerdir (22). Çapraz pinlerin daha fazla torsiyonel direnç sağladığı gösterilmiştir (23). Dekker ve ark tarafından yayınlanan metaanalizde lateral ve çapraz pin konfigürasyonları karşıllaştırılmış, sonuç olarak her iki yöntem arasında fonksiyonel sonuçlar açısından fark gösterilememiştir (24). Bu çalışmada da Dekker ve ark'nın çalışmasına benzer sonuçlar elde edildi. Çalışmada iatrojenik sinir hasarı olmaması, mini insizyon yapılarak ulnar sinirin korunmasına bağlandı.

Kırık tipi, yumuşak doku interpozisyonu ve cerrahın deneyimi kapalı redüksiyonun gerçekleştirilememesi üzerinde etkilidir. Weiland ve ark açık redüksiyonun sonuçlarının kapalı redüksiyonla benzer olduğunu bildirmişlerdir (25). Levine ve ark Gartland tip 3 kırıklara uygun şekilde müdahale edilirse açık redüksiyonun kapalı redüksiyona benzer sonuçlarının olduğunu, fakat enfeksiyon, malunion ve nörovasküler komplikasyon riskinin çok az arttığını göstermişlerdir (26). Kızllay ve ark kapalı redüksiyon başarısız olduğunda uygulanan lateral ve medial açık redüksiyonların sonuçlarının kapalı redüksiyona benzer olduğunu göstermişlerdir (16). Aktekin ve ark hareket kısıtılığının kapalı redüksiyonla kıyaslandığında açık 
redüksiyonda daha fazla olduğunu bildirmişlerdir (27). Li ve ark ise açık redüksiyon sonrasında redüksiyon kaybı insidansının daha az olduğunu bulmuşlardır (28). Sibly ve ark kapalı- açık redüksiyon arasında kubitus varus veya dirsek eklem hareket kısıtııığı açısından fark bulamamışlardır (29). Bu çalışmada açık redüksiyon uygulanan hastalarda Flynn kriterlerine göre daha fazla oranda kötü sonuçlar elde edildi, bu sonuç açık redüksiyon uygulanan hastalarda yaralanmanın daha ciddi olmasına bağlandı. Hasta sayısının azlığı, takip süresinin kısalığı, açık redüksiyon grubunun kapalı redüksiyon gerçekleştirilemeyen hastalardan oluşması ve retrospektif olması çalışmanın limitasyonlarıdır.

Sonuç olarak, suprakondiler humerus kırıklarının tedavisinde kapalı ve açık redüksiyon sonrasında pinlerle fiksasyon etkili ve güvenli bir tedavi yöntemidir. Öncelikle kapalı redüksiyon için çaba gösterilmelidir, fakat kapalı redüksiyon sağlanamazsa açık redüksiyon ve pinleme de tatminkar sonuçlar sunar. Bu çalışmada kapalı- açık redüksiyonla tedavi edilen hastaların klinik sonuçları arasında anlamlı fark tespit edilmedi. Kapalı- açık redüksiyonun sonuçlar üzerine etkisini daha iyi değerlendirebilmek için, daha fazla sayıda hasta içeren prospektif çalışmalar yapıllabilir.

Çıkar çatışması beyanı: Yazarın ticari bağlantısı yoktur. Çalışma için destek veren kurum yoktur. Yazarın herhangi bir ticari ürün, ilaç veya firma ile ilişkisi yoktur.

\section{Kaynaklar}

1. Zorrilla S de Neira J, Prada-Canizares A, Marti-Ciruelos R, Pretell-Mazzini J. Supracondylar humeral fractures in children: current concepts for management and prognosis. Int Orthop. 2015;39:2287-96.

2. Khoshbin A, Leroux T, Wasserstein D, Wolfstadt J, Law PW, Mahomed N, et al. The epidemiology of paediatric supracondylar fracture fixation: a population-based study. Injury. 2014; 45:701-8.

3. Mulpuri K, Wilkins $\mathrm{K}$. The treatment of displaced supracondylar humerus fractures: evidence-based guideline. J Pediatr Orthop. 2012; 32 (Suppl 2): S143-S152.

4. Gartland JJ. Management of supracondylar fractures of the humerus in children. Surg Gynecol Obstet. 1959;145-54.

5. Skaggs DL, Hale JM, Bassett J, Kaminsky C, Kay RM, Tolo VT. Operative treatment of supracondylar fractures of the humerus in children. The consequences of pin placement. J Bone Joint Surg Am. 2011;83-A:735-40.

6. Campbell CC, Waters PM, Emans JB, Kasser JR, Millis MB. Neurovascular injury and displacement in type III supracondylar humerus fractures. J Pediatr Orthop. 1995;15(1):47-52.

7. Baratz $M$, Micucci $C$, Sangimino $M$. Pediatric supracondylar humerus fractures. Hand Clin. 2006; 22(1):69-75.

8. Reitman RD, Waters $P$, Millis $M$. Open reduction and internal fixation for supracondylar humerus fractures in children. J Pediatr Orthop. 2001;21(2):157-161.

9. Chen TL, He CQ, Zheng TQ, Gan YQ, Huang MX, Zheng YD, Zhao JT. Stiffness of various pin configurations for pediatric supracondylar humeral fracture: a systematic review on biomechanical studies. J Pediatr Orthop B. 2015;24(5):389-99.

10. Worlock P. Supracondylar fractures of the humerus. Assessment of cubitus varus by the Baumann angle. J Bone Joint Surg Br. 1986; 68(5):755-757

11. Flynn JC, Matthews JG, Benoit RL. Blind pinning of displaced supracondylar fractures of the humerus in children. Sixteen years'experience with long-term follow-up. J Bone Joint Surg Am. 1974;56:263-72.

12. Howard A, Mulpuri K, Abel MF, et al. American Academy of Orthopaedic Surgeons. The treatment of pediatric supracondylar humerus fractures. J Am Acad Orthop Surg. 2012;20(5):320e327.
13. Loizou CL, Simillis C, Hutchinson JR. A systematic review of early versus delayed treatment for type III supracondylar humeral fractures in children. Injury. 2009;40(3):245-8.

14. Walmsley PJ, Kelly MB, Robb JE, et al. Delay increases the need for open reduction of type-III supracondylar fractures of the humerus. J Bone Joint Surg $\mathrm{Br}$. 2006;88(4):528e530.

15. Wingfield JJ, Ho CA, Abzug JM, Ritzman TF, Brighton BK. Open Reduction Techniques for Supracondylar Humerus Fractures in Children. J Am Acad Orthop Surg. 2015;23(12):e72-80.

16. Kızılay YO, Aktekin CN, Özsoy MH, Akşahin E, Sakaoğullar A, Pepe M, Kocadal O. Gartland Type 3 Supracondylar Humeral Fractures in Children: Which Open Reduction Approach Should Be Used After Failed Closed Reduction? J Orthop Trauma. 2017;31(1):e18-e23.

17. Payvandi SA, Fugle MJ. Treatment of pediatric supracondylar humerus fractures in the community hospital. Tech Hand Up Extrem Surg. 2007;11(2):174-8.

18. Kao HK, Lee WC, Yang WE, Chang $\mathrm{CH}$. Clinical significance of anterior humeral line in supracondylar humeral fractures in children. Injury. 2016;47(10):2252-2257.

19. Slobogean BL, Jackman H, Tennant S, Slobogean GP, Mulpuri K. latrogenic ulnar nerve injury after the surgical treatment of displaced supracondylar fractures of the humerus: number needed to harm, a systematic review. J Pediatr Orthop. 2010;30(5):430-6.

20. Woratanarat $P$, Angsanuntsukh $C$, Rattanasiri $S$, Attia J, Woratanarat $T$, Thakkinstian A. Meta-analysis of pinning in supracondylar fracture of the humerus in children. J Orthop Trauma. 2012;26:48-53.

21. Hamdi A, Poitras P, Louati H, Dagenais S, Masquijo JJ, Kontio K. Biomechanical analysis of lateral pin placements for pediatric supracondylar humerus fractures. J Pediatr Orthop. 2010;30:135-9.

22. Zamzam MM, Bakarman KA. Treatment of displaced supracondylar humeral fractures among children:crossed versus lateral pinning. Injury. 2009;40(6):625-630.

23. Zionts LE, McKellop HA, Hathaway R. Torsional strength of pin configurations used to fix supracondylar fractures of the humerus in children. J Bone Joint Surg Am. 1994;76:253-6.

24. Dekker $A E$, Krijnen $P$, Schipper IB. Results of crossed versus lateral entry K-wire fixation of displaced pediatric supracondylar humeral fractures: A systematic review and meta-analysis. Injury. 2016;47(11):2391-2398. doi: 10.1016/j.injury.2016.08.022.

25. Weiland AJ, Meyer S, Tolo VT, Berg HL, Mueller J. Surgical treatment of displaced supracondylar fractures of the humerus in children. Analysis of fifty-two cases followed for five to fifteen years. J Bone Joint Surg Am. 1978;60(5):657-661.

26. Lewine E, Kim JM, Miller PE, Waters PM, Mahan ST, Snyder B, Hedequist D, Bae DS. Closed Versus Open Supracondylar Fractures of the Humerus in Children: A Comparison of Clinical and Radiographic Presentation and Results. J Pediatr Orthop. 2018;38(2):77-81.

27. Aktekin CN, Toprak A, Ozturk AM, et al. Open reduction via posterior triceps sparing approach in comparison with closed treatment of posteromedial displaced Gartland type III supracondylar humerus fractures. J Pediatr Orthop B. 2008;17:171-178.

28. Li YA, Lee PC, Chia WT, et al. Prospective analysis of a new minimally invasive technique for paediatric Gartland type III supracondylar fracture of the humerus. Injury. 2009; 40:1302-1307.

29. Sibly TF, Briggs PJ, Gibson MJ. Supracondylar fractures of the humerus in childhood: range of movement following the posterior approach to open reduction. Injury. 1991;22:456-458. 